\title{
Hydrological modelling for conjunctive water use in the Murrumbidgee Catchment: groundwater recharge estimation
}

\author{
$\underline{\text { Ruirui Zhu}}^{1}$, Anthony J. Jakeman ${ }^{1}$ and B.F.W. Croke ${ }^{2}$ \\ ${ }^{1}$ Fenner School of Environment and Society, Australian National University, Canberra, ACT 0200, Australia \\ ${ }^{2}$ Mathematical Sciences Institute, Australian National University, Canberra, ACT 0200, Australia \\ Email:Ruirui.zhu@anu.edu.au
}

\begin{abstract}
Many regions of the world are under the stress of water scarcity. The stress is intensifying due to population and economic growth, and further exacerbated by global climate change. There is growing awareness of the need to manage surface water and groundwater in a more holistic way, that is conjunctively, which requires better understanding of the interactions between surface water and groundwater. Groundwater recharge is a vital interaction process and quantifying its amount in situations of interest needs considerable investigation. Recharge estimation, however, is fraught with uncertainty since the recharge process is full of complexity and plagued by heterogeneity and scale issues, and so benefits from use of multiple methods to help infer its range of possible values. Available estimation techniques include approaches that are physical, chemical and mathematical or a combination of them. Chemical and physical methods usually are expensive and their feasibility is limited to point or small scales. Numerical modelling is widely considered as an effective tool because of its potential to predict recharge rates in space and time. In this paper, we investigate a purely hydrological surface modelling approach, combined with extraction of recession-flow signals from their associated hydrographs, as one way to help appreciate the amount of recharge occurring in a catchment. Two hydrological models (SIMHYD and GR4J), one with and one without direct representation of the recharge process, are used to estimate groundwater recharge in unregulated sub-catchments in the Murrumbidgee catchment for the period 1976-2011. In addition, groundwater recharge is also estimated using the empirical and non-process-based RORA approach on the basis of daily streamflow observations and predictions. The results show that when the hydrological models are well calibrated, a notion of recharge can be estimated via the RORA approach applied to the model predictions, thereby circumventing the situation where the hydrological model itself has not included representation of the recharge process. For the hydrological model SIMHYD which has the recharge process represented, the recharge output directly from the model matches to a reasonable extent that derived from simulated streamflow using RORA. The results imply that surface hydrological modelling together with recession analysis using methods like RORA can be a useful adjunct to other methods to infer notional groundwater recharge to support decision-making on conjunctive water use.
\end{abstract}

Keywords: Groundwater recharge, hydrological modelling, RORA approach, conjunctive water use, Murrumbidgee catchment 
Zhu et al., Hydrological modelling for conjunctive water use in the Murrumbidgee Catchment: groundwater recharge estimation

\section{INTRODUCTION}

In many regions of the world, the stress of water scarcity is intensifying due to population and economic growth, and further exacerbated by global climate change (Jacob et al., 2014; Lobell, 2008, van Vliet et al., 2013). For more effective and efficient management of water resources, there is growing awareness of the needs to manage surface water and groundwater in a holistic way and to develop schemes for conjunctive water use (Gleeson et al., 2010). The challenges of conjunctive water use largely rely on knowledge of the interactions between surface water and groundwater (Gleeson et al., 2010, 2012; Hartmann et al., 2017). The recharge process, in which surface water moves downward into the groundwater system, is a vital interaction process that needs considerable investigation and can be influenced by climate, hydrology, geomorphology (including topography, soil, and vegetation), and geology (Freeze \& Cherry, 1979).

Recharged water is renewable groundwater that can be crucial to support sustainable management of regional water resources (Crosbieet al., 2013; Gleeson et al., 2010, 2012). Rational estimation of recharge is difficult since the recharge process is full of complexity and plagued by heterogeneity and scale issues. Available estimation techniques include approaches that are physical (Owor et al., 2009), chemical (Scanlon et al., 2012), and mathematical (Andermann et al., 2012; Crosbie et al., 2013; Hartmannet al., 2017) or a combination of them. Chemical and physical methods usually are expensive and their feasibility is limited to point or smaller scale. Numerical modelling is widely considered as an effective tool because of its potential to predict recharge rates in space and time. Among the numerical models, rainfall-runoff modeling is one of the candidates widely used to estimate regional groundwater recharge (Andermann et al., 2012; Arnold et al., 2000; Crosbie et al., 2013; Döll \& Fiedler, 2008; Hartmann et al., 2017; Healy, 2011; Scanlon, 2002). However, the modelling approach usually requires observations for model calibration and validation, which are not always available. Recharge can also be estimated by the analysis of recession flow when daily streamflow observation is available, for example the RORA approach proposed by Rorabaugh (1964). More often, the recession analysis method is more convenient and applicable because of relative abundancy of streamflow data (Brutsaert, 2008; Rutledge, 2007).

This paper aims to evaluate the performance of hydrological models in the estimation of groundwater recharge. It will firstly be estimated using the RORA approach on the basis of observed streamflow, and used as a benchmark for model evaluation. Two hydrological models (SIMHYD and GR4J) are invoked with the consideration of the different representation of the recharge process in the model structure.

\section{STUDY AREA AND DATA}

The Murrumbidgee River catchment (MRC) contains the second largest river in the Murray-Darling systemand has great environmental value for both local rivers and areas downstream in the Murray-Darling River system. It has an area of $84000 \mathrm{~km}^{2}$ with the Murrumbidgee River being approximately $1600 \mathrm{~km}$ long (Fig.1). The climate is extremely diverse ranging from alpine conditions in the headwaters of the Snowy Mountains to the semi-arid conditions of the Riverina plains in the west. Average annual potential evaporation is about 1000-1900 mm while annual rainfall is between $300-1700 \mathrm{~mm}$. Most rainfall and natural runoff occur in winter and early spring. Most of the inflow to the Murrumbidgee River comes from the catchment upstream of Wagga Wagga. Land use in the MRC is also diverse. Dryland grazing and cropping account for more than $75 \%$ of land use but some $5 \%$ is irrigated. Almost $75 \%$ of the MRC is heavily regulated to supply water for irrigation, stock and domestic, urban water demand, and environmental requirements. The fraction of available water use which has been developed in this region is up to $53 \%$ and about $17 \%$ of total water use is from groundwater. In dry years, groundwater represents $26 \%$ of total water use.

In this paper, we analyse data from 26 unregulated sub-catchments in the Murrumbidgee catchment. Time series of daily rainfall and potential evapotranspiration at $0.05^{\circ}$ resolution for 1976-2011 are derived from the SILO Data Drill (Jeffrey et al., 2001; www.longpaddock.qld.gov.au/silo). In order to calibrate the hydrological models, daily streamflow data for 26 sub-catchments (see Fig.1) were gathered from the New South Wales Department of Primary Industries. The 26 sub-catchments cover areas of $85 \mathrm{~km}^{2}$ to $2650 \mathrm{~km}^{2}$. 
Zhu et al., Hydrological modelling for conjunctive water use in the Murrumbidgee Catchment: groundwater recharge estimation

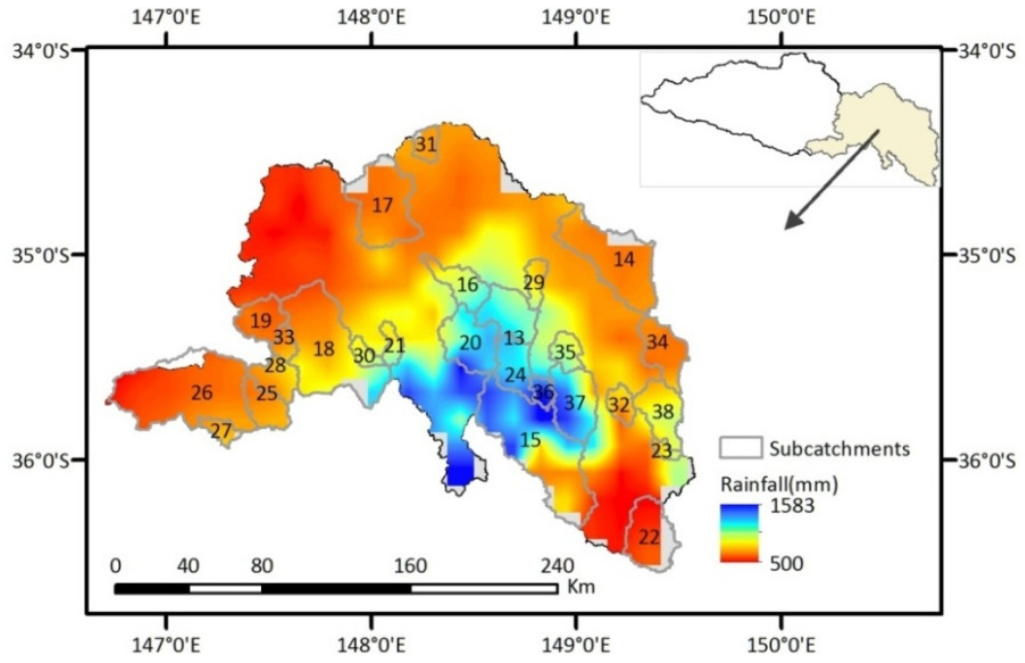

Figure 1. Sketch map of the unregulated sub-catchments in the Murrumbidgee catchment included in this study

\section{METHODOLOGY}

\subsection{Hydrological modelling}

The 4-parameter GR4J (Perrin et al., 2003) and 9-parameter SIMHYD (Chiew \& McMahon, 1991) surface hydrological models were used in this research. The GR4J model simulates both movement of water through the soil zone and runoff routing, but without explicit expression of the recharge process in its model structure, resulting in no direct recharge estimation as model output. The SIMHYD model computes interception loss, soil moisture, and recharge into the vadose zone, whereby the water into the vadose zone is considered as groundwater recharge. The GR4J and the SIMHYD models are optimized using the SCE-UA (Duan, 1994) evolutionary algorithm to maximize the Nash-Sutcliffe Efficiency (NSE) statistic against daily streamflow observations.

\subsection{RORA approach}

To estimate the recharge to groundwater in this study, in addition to the method based on the two hydrological models, the RORA method (Rorabaugh, 1964) was applied. In the RORA method, the potential groundwater discharge to the stream is assumed equal to approximately one-half of the total volume of water that recharges the system at critical time $T_{c}$ after peak during the recharge event. Combined with the principle of superposition, the total recharge can be calculated by the following equation (Glover, 1964; Rutledge, 2007):

$$
R_{c}=-2\left(Q_{2}-Q_{1}\right) / \ln K
$$

where $R_{c}$ is the total volume of recharge due to the event $\left(\mathrm{L}^{3}\right) ; Q_{1}$ and $Q_{2}$ are groundwater discharge at critical time $T_{c}$ as extrapolated from the previous and current streamflow recession curve $\left(\mathrm{L}^{3} / \mathrm{T}\right)$, respectively. Critical time $T_{c}$ is closely related to the recession constant $K$, which can be expressed as.

$$
T_{c}=-0.2144 \times\left(1 / \log _{10} K\right)
$$

The recession constant $K$ can be derived by the Mater Recession Curve method (Rutledge, 2007; Zhu et al., 2010), where the recession of streamflow after a recharge event is assumed to follow the exponential function:

$$
Q_{t}=Q_{0} e^{-\alpha t}
$$

where $Q_{0}$ is the initial discharge of the recession curve; $Q_{t}$ is the discharge at $t$ time after $Q_{0}$; and $a$ is a constant known as the recession coefficient. Usually, the term $\exp (-a)$ is denoted by $K$ and is called the recession constant.

It is worth noting that the RORA method aims to provide the net recharge, which is diffuse areal recharge to the water table minus losses (leakage to a deeper aquifer, ground-water evapotranspiration, extractions). The 
Zhu et al., Hydrological modelling for conjunctive water use in the Murrumbidgee Catchment: groundwater recharge estimation

method is appropriate if all or most ground water in the basin discharges to the stream except for that which is lost to riparian evapotranspiration, and if a streamflow-gauging station at the downstream end of the basin measures all or most of this outflow. It means that if the streamflow is regulated, bias could exist in the estimated recharge based on observed streamflow. Therefore, in this paper, only the recharge of the unregulated catchments is investigated to be consistent with the limitations of the RORA approach.
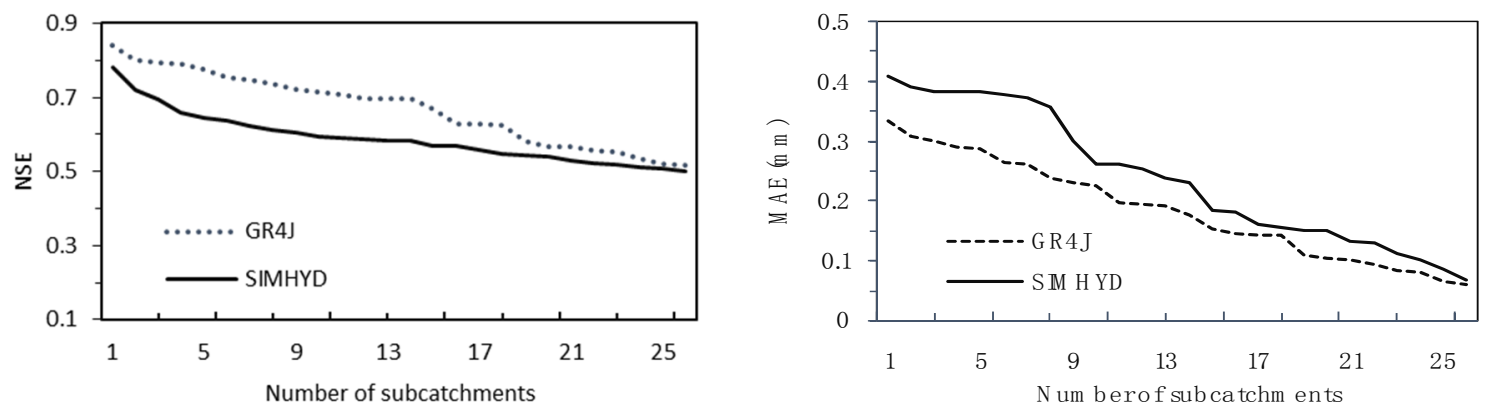

Figure 2. Calibration performance of SIMHYD and GR4J models for 26 unregulated sub-catchments

\section{RESULTS}

\subsection{Performance of the hydrological models}

Fig. 2 shows the calibration performance of the GR4J and SIMHYD models in simulating daily streamflow for the period 1976-2011for the 26 individual sub-catchments. In general, both models can satisfactorily reproduce daily streamflow in terms of the widely used NSE and MAE statistics for a perfect fit. MAE is the average of the absolute difference between observations and predictions. The NSE value is in the range 0.52-0.84 for GR4J ( 0.67 on average), and 0.50-0.79 for SIMHYD ( 0.59 on average), respectively. The MAE value varies about $0.06-0.33 \mathrm{~mm}$ for GR4J $(0.18 \mathrm{~mm}$ on average), and $0.07-0.41 \mathrm{~mm}$ for SIMHYD $(0.23 \mathrm{~mm}$ on average), respectively. GR4J shows higher NSE values and lower MAE values than SIMHYD for all sub-catchments. For GR4J, 14 out of the 26 sub-catchments have NSE values higher than 0.7 and 16 sub-catchments have MAE values less than $0.2 \mathrm{~mm}$, while the SIMHYD model has only 3sub-catchments with high NSE $(>0.7)$ and 12 sub-catchments with low $\mathrm{MAE}(<0.2 \mathrm{~mm})$. The reasonable performance of the hydrological models provides some confidence in them being useful for further estimation of groundwater recharge when based on the simulated streamflow.

\subsection{Groundwater recharge estimation based on observed streamflow}

Figs. $3 \mathrm{a}$ and $3 \mathrm{~b}$ show respectively the estimated groundwater recharge and the recharge coefficient (i.e. ratio of recharge to rainfall) using the RORA method, on the basis of observed streamflow only, for the 26 sub-catchments. The estimated mean annual recharge of the sub-catchments ranges from 6.4-321.2 mm with an average of $81.9 \mathrm{~mm}$. Meanwhile, the recharge coefficient varies from 0.009 to 0.26 with an average of 0.07 . The sub-catchment No.31 in the north has the lowest recharge $(6.4 \mathrm{~mm})$ and recharge coefficient of 0.009 . The sub-catchments with the higher recharge are in the southern part. In general, sub-catchments with higher precipitation tend to have more recharge and higher recharge coefficients. However, as can be seen from Fig.3, the spatial patterns of recharge and recharge coefficient are quite similar, which implies that, besides rainfall, the recharge coefficient could also be affected by other hydrogeological factors like surface topography, land use, alluvial thickness, transmissivity, and hydraulic conductivity. 
Zhu et al., Hydrological modelling for conjunctive water use in the Murrumbidgee Catchment: groundwater recharge estimation
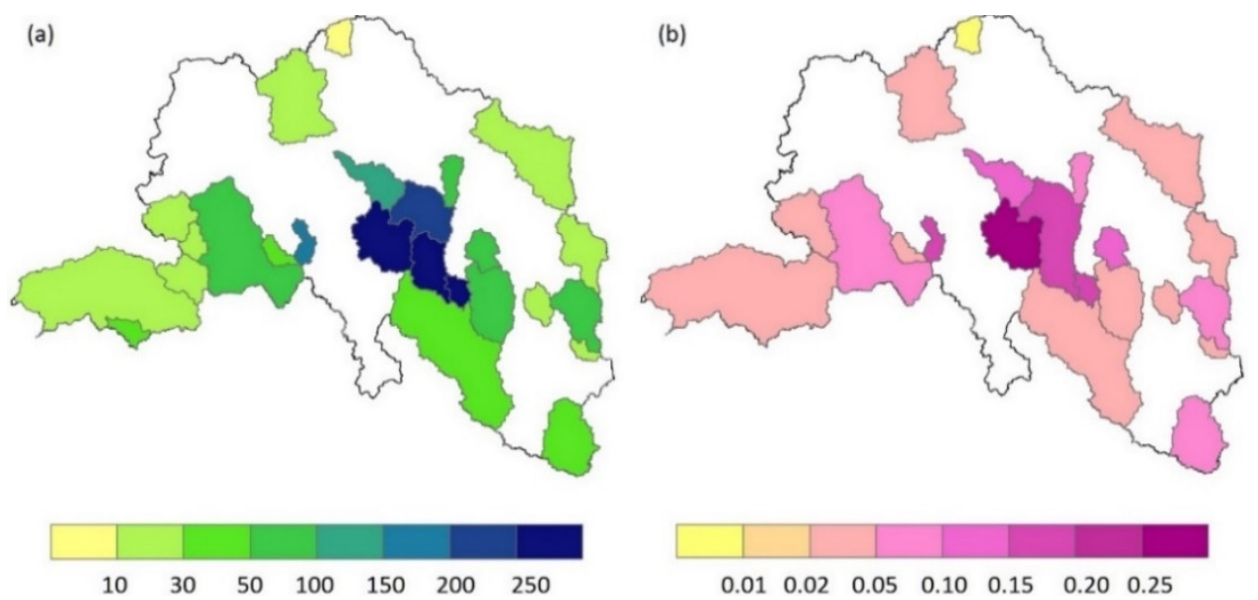

Figure 3. Estimated groundwater recharge $(\mathrm{mm})(\mathrm{a})$, and the recharge coefficient (b) of 26 sub-catchments in the upper Murrumbidgee basin
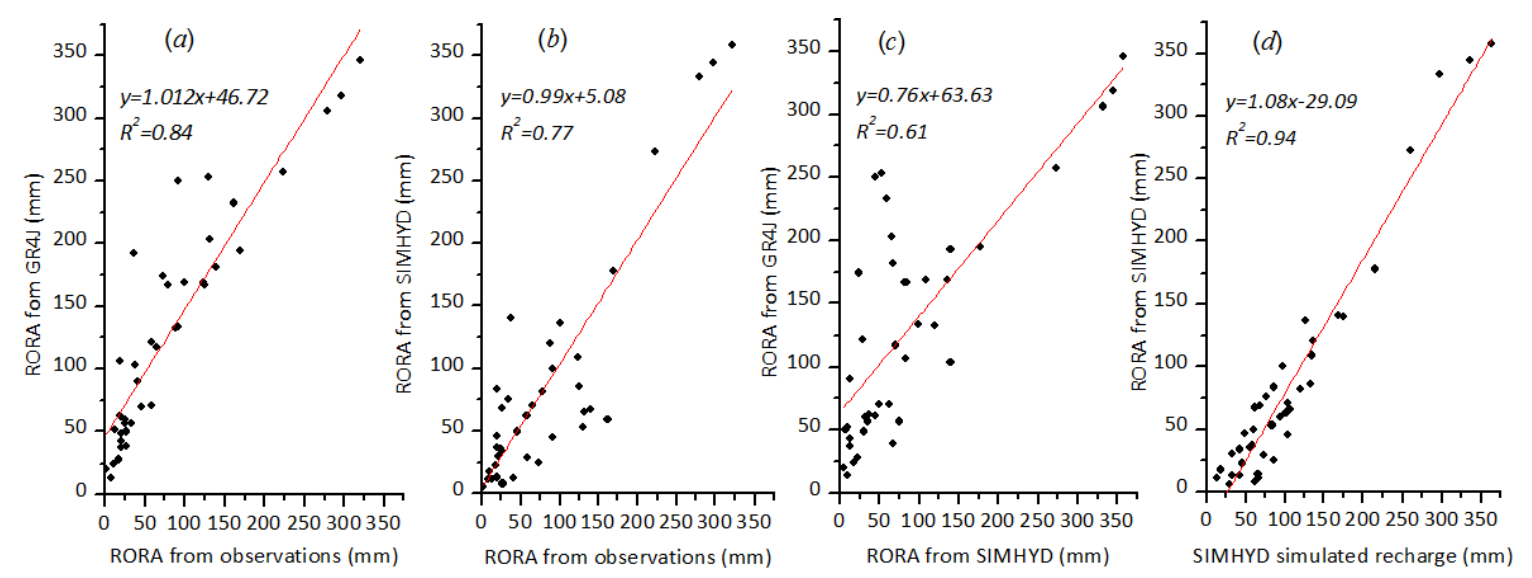

Figure 4. Comparison of groundwater recharge estimates. (a): RORA based on GR4J simulated streamflow against RORA based on observed streamflow; (b): RORA based on SIMHYD simulated streamflow against RORA based on observed streamflow; (c): RORA based on GR4J simulated streamflow against that for SIMHYD; (d): RORA based on SIMHYD simulated streamflow against SIMHYD simulated recharge.

\subsection{Groundwater recharge estimation based on simulated streamflow}

Hydrological models may or may not include a recharge component process in their representation. However, if the model can provide satisfactory simulation of daily streamflow, the groundwater recharge can also be estimated using the recession analysis approach like RORA. Figs.4a and $4 \mathrm{~b}$ compare the estimated recharge from observed streamflow and that from simulated streamflow by GR4J and SIMHYD. As illustrated in the figures, it is obvious that estimated recharge from both SIMHYD and GR4J (whose predictions feed RORA) are in strong agreement with that derived from observed streamflow. It indicates that although GR4J and SIMHYD have vastly different assumptions in their model structure, when the models are well calibrated, they can produce quite consistent recharge estimates, when incorporated with the RORA method. Though there is good agreement between GR4J and SIMHYD modelling $\left(\mathrm{R}^{2}=0.61\right.$, see Fig.4c), comparatively, recharge estimates basing on GR4J show closer relation to that basing on observed streamflow $\left(\mathrm{R}^{2}=0.84\right.$ vs 0.77 ), which is because GR4J in general performs better than SIMHYD in terms of reproducing daily streamflow for all the sub-catchments. As also shown in Fig.4d, for SIMHYD which includes a recharge model component, the direct recharge output matches well with the RORA estimate based on simulated streamflow $\left(\mathrm{R}^{2}=0.94\right)$. The results further demonstrate that when reliable daily streamflow (observed or simulated) are available, the RORA approach can be used to estimates of groundwater recharge, albeit with its associated uncertainty due to the underlying empirical assumptions. 
Zhu et al., Hydrological modelling for conjunctive water use in the Murrumbidgee Catchment: groundwater recharge estimation

\section{SUMMARY}

Recharge is an important factor in evaluate groundwater resources and manage water resources in a sustainable way. However, it is difficult to quantify recharge and estimation of recharge is fraught with uncertainty. Hydrological models can be a useful adjunct to other methods to estimate groundwater recharge when the model explicitly includes the recharge component and is well calibrated. For hydrological models without a recharge component, their simulated streamflow can also be used to estimate groundwater recharge if an auxiliary (empirical) approach like RORA is applied. Meanwhile, given observed streamflow, the RORA approach can be used independently to provide a notional recharge estimation to validate that estimated using hydrological models. To improve the performance of hydrological models in recharge estimation, it could be useful to calibrate the model against the RORA recharge estimated from observed streamflow. The advantage of approaches like RORA is that they require only daily streamflow. However, for catchments without streamflow records, the direct RORA approach becomes inapplicable. In such a case, hydrological models together with methods like RORA could provide an alternative solution. Furthermore, hydrological models together with RORA can also be used to explore the impact of climate change and land use change on groundwater recharge.

\section{REFERENCES}

Arnold, J.G., R.S. Muttiah, R. Srinivasan, and P.M. Allen, (2000). Regional estimation of base flow and groundwater recharge in the Upper Mississippi river basin. Journal of Hydrology, 227(1): 21-40.

Andermann, C., Longuevergne, L., Bonnet, S., Crave, A., Davy, P. and Gloaguen, R. (2012). Impacts of transient groundwater storage on the discharge of Himalayan Rivers. Nature geosciences, 5:127-132.

Brutsaert, W. (2008). Long-term groundwater storage trends estimated from streamflow records: Climatic perspective.Water Resources Research,44, W02409.

Chiew, F.H.S. and McMahon, T.A. (1991). Improved modelling of the groundwater processes in hydrology. Proceedings of the 20th Hydrology and Water Resources Symposium, Perth, October 1991, Institute of Engineers Australia, 492-497.

Crosbie, R. S., Scanlon, B. R., Mpelasoka, F. S., Reedy, R. C. et al. (2013). Potential climate change effects on groundwater recharge in the High Plains Aquifer, USA, Water Resources Research, 49, 3936-3951.

Döll, P. and Fiedler, K. (2008). Global-scale modeling of groundwater recharge. Hydrol. Earth. Syst. Sci.

12(3):863-885.

Duan, Q.A., Sorooshian, S., and Gupta, V.K. 1994. Optimal use of the SCE-UA global optimization method for calibrating watershed models. Journal of Hydrology, 158, 265-284.

Freeze, R. and Cherry, J. (1979). Groundwater: Englewood Cliffs, N.J., Prentice-Hall, 604.

Gleeson T, et al. (2010). Groundwater sustainability strategies. Nature geosciences, 3(6):378-379.

Gleeson, T., Wada, Y., Bierkens, M.F. and van Bee, k L.P. (2012). Water balance of global aquifers revealed by groundwater footprint. Nature, 488(7410):197-200.

Glover, R.E. (1964). Groundwater movement: U.S. Bureau of Reclamation Engineering Monograph Series, 31: 31-34.

Hartmann, A., Gleeson, T., Wada, Y., Wagener, T. (2017). Enhanced groundwater recharge rates and altered recharge sensitivity to climate variability through subsurface heterogeneity. Proc. Natl. Acad. Sci. USA, 114(11):2842-2847.

Healy, R.W. (2011). Estimating groundwater recharge. Cambridge University Press, Cambridge, UK

Jacob, S., Jens, H., Dieter, G., Ingjerd, H., Nigel, W.,Arnell, et al. (2014). Multi-model assessment of water scarcity under climate change.Proc. Natl. Acad. Sci. USA, 111(9), 3245-3250.

Jeffrey, S.J., Carter, J.O., Moodie, K.B. and Beswick, A.R. (2001). Using spatial interpolation to construct a comprehensive archive of Australian climate data, Environmental Modelling and Software, 16/4, 309-330.

Lobell, D., Burke, M., Tebaldi, C., Mastrandera, M., Falcon, W. and Naylor, R. (2008). Prioritizing climate change adaptation needs for food security in 2030. Science, 319 (5863): 607-610. 
Zhu et al., Hydrological modelling for conjunctive water use in the Murrumbidgee Catchment: groundwater recharge estimation

Owor, M., Taylor, R. G., Tindimugaya, C. and Mwesigwa, D. (2009). Rainfall intensity and groundwater recharge: empirical evidence from the Upper Nile Basin. Environmental research letter, 4035009.

Perrin, C., Michel, C., and Andreassian, V. (2003). Improvement of a parsimonious model for stream flow simulation. Journal of Hydrology, 279(1-4):275-289.

Rorabaugh, M.I. (1964). Estimating changes in bank storage and groundwater contribution to streamflow. International Association of Scientific Hydrology, 63(1):432-441.

Rutledge A.T. (2007). Computer programs for describing the recession of ground-water discharge and for estimating mean ground-water recharge and discharge from streamflow records-update.U. S. Geological Survey Water Resources Investigations Report, 2007:98-4148.

Scanlon, B.R., Faunt, C.C., Longuevergne, L.et al. (2012). Groundwater depletion and sustainability of irrigation in the US High Plains and Central Valley, Proc. Natl. Acad. Sci., 109(24), 9320-9325.

Scanlon, B.R., Healy, R.W., and Cook, P.G. (2002). Choosing appropriate techniques for quantifying groundwater recharge. Hydrogeology Journal, 10, 18-39.

vanVliet, M. T. H., Franssen, W. H. P., Yearsley, J. R., et al. (2013). Global river discharge and water temperature under climate change. Global environmental change, 23(2): 450-464.

Zhu, R.R., Zheng, H.X. and Liu, C.M. (2010). Estimation of groundwater residence time and recession rate in watershed of the Loess Plateau. Journal of Geographical Sciences, 20(2): 273-282. 